Supporting Information (4 pages, 2 Figures) for:

\title{
Biogenic $\alpha-\mathrm{Fe}_{2} \mathrm{O}_{3}$ nanoparticles enhance the biological activity of Trichoderma against the plant pathogen Sclerotinia sclerotiorum
}

Natalia Bilesky-Josét, Cintia Maruyama ${ }^{\ddagger}$, Tais Germano-Costa ${ }^{\dagger}$,Estefânia Campos ${ }^{\prime \prime}$, Lucas Carvalho ${ }^{\ddagger}$, Renato Grillo", Leonardo Fraceto $*$, Renata de Lima* ${ }^{*}$

$\dagger$ Laboratory of Bioactivity Assessment and Toxicology of Nanomaterials, University of Sorocaba (UNISO), Rodovia Raposo Tavares, km 92.5, Sorocaba, São Paulo, 18023 000, Brazil

¥ São Paulo State University (UNESP), Institute of Science and Technology, Av. Três de Março, 511, Aparecidinha, Sorocaba, São Paulo, 18087-180, Brazil

${ }^{\Psi}$ Human and Natural Sciences Center, Federal University of ABC, Av. dos Estados, 5001, B1. A, T3, Lab. 503-3, Bangú, Santo André, São Paulo, Brazil

" São Paulo State University (UNESP), Department of Physics and Chemistry, School of Engineering, Av. Brasil, 56, Ilha Solteira, São Paulo, 15385-000, Brazil

* Corresponding author: renata.lima@prof.uniso.br

\section{Content}

Methods for Allium cepa assay and evaluation of the nanoparticles effects on seed

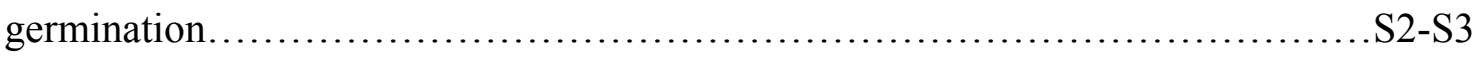

Results for the Allium cepa assay........................................... 3

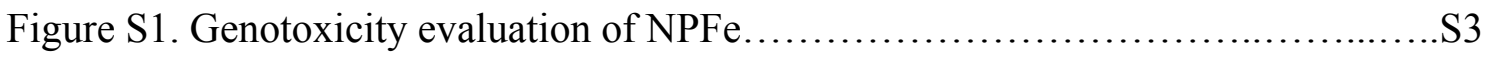

Results for the evaluation of the nanoparticles effects on seed germination............S4

Figure S2. Germination index of seeds exposed to NPFe..........................S4

\section{Allium cepa assay}


The $A$. cepa assay was carried out based on the methodology described by

Fiskesjö $^{1}$, in which roots of $A$. cepa were exposed to nanoparticles in the concentration of $5,0 \times 10^{7} \mathrm{NPs} . \mathrm{mL}^{-1}$ and to a solution of $T$. harzianum at 127 $\mu \mathrm{g} \cdot \mathrm{mL}^{-1}$ for $24 \mathrm{~h}$, and then fixed in ethanol: acetic acid (3: $1 \mathrm{v}$ : v). After fixation, the roots were hydrolyzed with $1 \mathrm{M} \mathrm{HCl}\left(60^{\circ} \mathrm{C}\right)$, and stained with Schiff's reagent. The slides were prepared by crushing the meristematic region of the roots with 2\% Carmine acetic dye. The analysis was performed by counting the cells, considering the phases of cell division and the damage present in these phases. The samples were analyzed in triplicate and a negative control was used, in which the roots were exposed to distilled water.

For the evaluation, mitotic indices (number of dividing cells / total cells) and chromosomal alteration index (number of damaged cells / dividing cells) were calculated. Relative indices were also calculated, where each index obtained was divided by the index found in the control.

\section{Phytotoxicity}

\section{Evaluation of the nanoparticles effects on seed germination}


In order to verify the viability of seeds exposed to $\mathrm{NpFe}$, a germination test of beans (Phaseolus vulgaris), lentils (Lens culinaris) and tomatoes (Solanum lycopersicum) was carried out, these are cultures that can be affected by the phytopathogen S. sclerotiorum.

For the test, the beans, lentils and tomatoes seeds were initially sterilized by immersion in $2 \%$ sodium hypochlorite for 15 minutes. Then they were washed and treated with suspensions of NpFe at 5,0 x 107 NP. mL-1, T. harzianum at 127 $\mu \mathrm{g} \cdot \mathrm{mL}^{-1}$ and a control with ultrapure water was also prepared. Twenty seeds were put in $15 \mathrm{~mL}$ of the suspensions, and remained in agitation at $150 \mathrm{rpm}$ for $1 \mathrm{hour}$. The seeds were then transferred to Petri dishes containing an agar layer (1.5\% $\mathrm{w} / \mathrm{v}$ ). The dishes were covered and kept in the dark at $25^{\circ} \mathrm{C}$. After 5 days, the seeds were removed from the dishes to check the germination index of each dish, the assay was performed in triplicate ${ }^{2}$. From the number of germinated seeds observed at the end of the test, a germination index was calculated (number of seeds germinated in the dish / number of total seeds in the dish).

\section{RESULTS}




\section{Allium cepa assay}

To verify the genotoxic effects of the nanoparticles and alterations in the mitotic indices, the $A$. cepa assay was performed, the results showed that the synthesized NpFe did not present significant changes in the Mitotic Index in relation to the control. However, exposure to T. harzianum caused a significant reduction in the mitotic index (Figure S1-SA). Regarding the Alteration Index, none of the samples showed a significant difference in relation to the control (Figure S1-SB).

Figure S1 - Genotoxicity evaluation of NPFe. (A) Relative Mitotic index. (B) Relative Alteration Index. The statistically significant difference considered is $p$ $<0.05$, distinct numbers represent a significant difference.

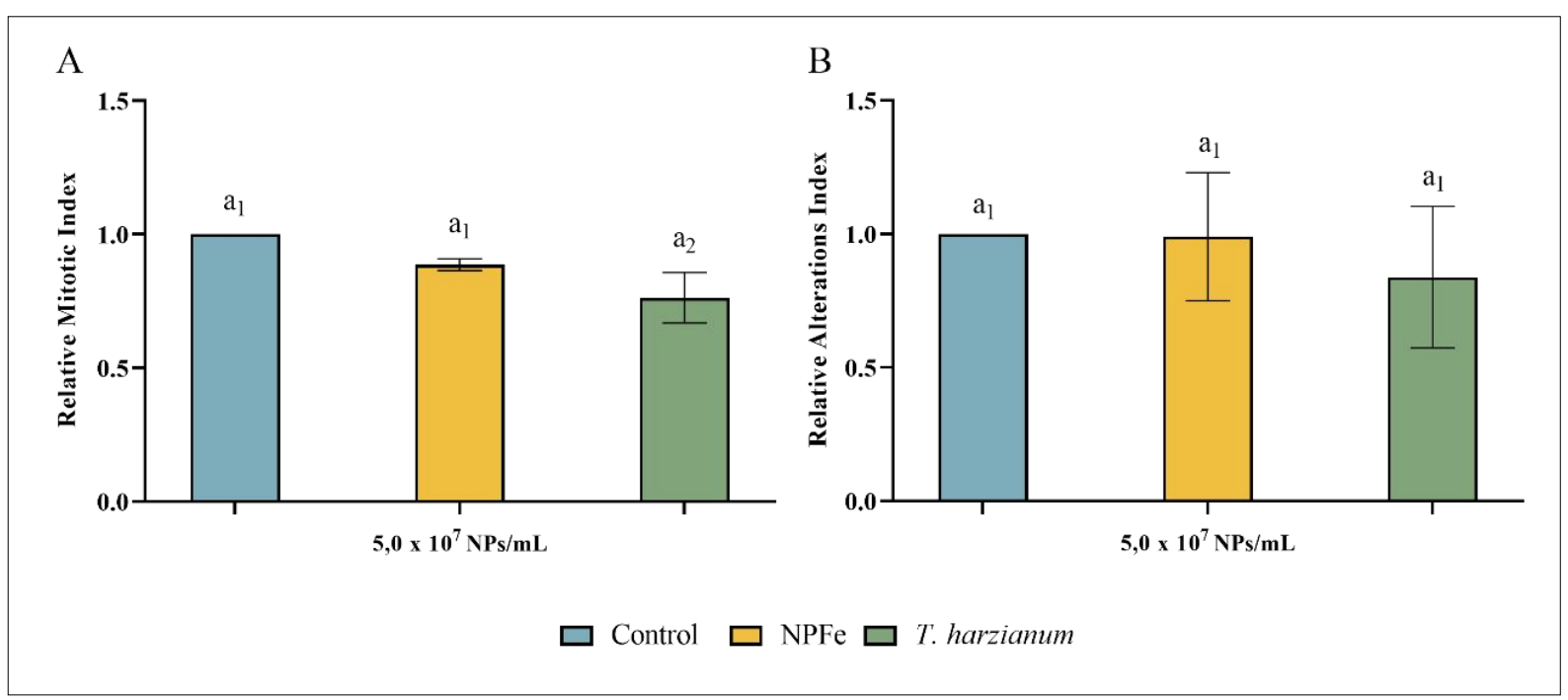




\section{Phytotoxicity}

\section{Evaluation of the effects of nanoparticles on germination}

There were no significant changes between germination rates, in relation to the control, in any of the seeds (Figure S2), indicating that the NPFe did not interfere in the germination of beans, lentils and tomatoes.

Figure S2 - Germination index of beans, lentils and tomatoes exposed to NPFe. The statistically significant difference considered is $p<0.05$, however, for this trial, the differences were not significant.

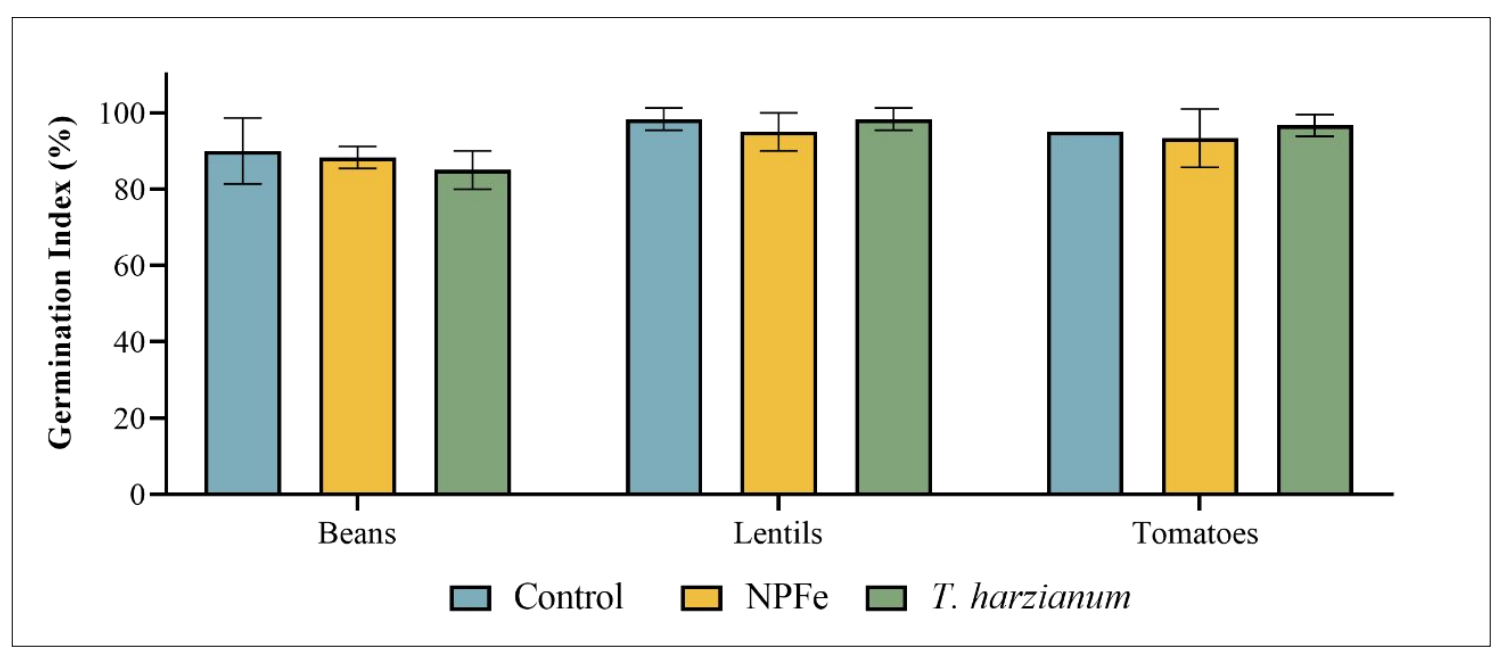

\section{REFERENCES}


(1) Fiskesjö, G. The Allium Test as a Standard in Environmental Monitoring. Hereditas 1985, 102 (1), 99-112. https://doi.org/10.1111/j.1601-

5223.1985.tb00471.x.

(2) Oliveira, J. L. de; Campos, E. V. R.; Pereira, A. E. S.; Pasquoto, T.; Lima, R.; Grillo, R.; Andrade, D. J. de; Santos, F. A. dos; Fraceto, L. F. Zein Nanoparticles as Eco-Friendly Carrier Systems for Botanical Repellents Aiming Sustainable Agriculture. J. Agric. Food Chem. 2018, 66 (6), 13301340. https://doi.org/10.1021/acs.jafc.7b05552. 